International Journal of Art and Design Education, 2007 26, 1

pp. $10-20$

\title{
Identity politics and the queering of art education: inclusion and the confessional route to salvation.
}

\author{
Nicholas Addison
}

\begin{abstract}
:
In this paper I discuss the relationship between theories of identity and making practices in secondary art and design. Of particular interest is the way students are invited to explore identities in relation to a sense of self and the extent to which this is informed by schools' concern to make diversity visible through multicultural celebration thus framing and possibly limiting exploration. It is notable that non-heternormative sexual identities remain largely invisible in the official curriculum and I examine the disjunction between this absence and their hypervisibilty in the mass media and its culture of confession/exposure. I revisit Michel Foucault's discussion of the history of sexuality as a way to understand the development of confessional discourses in modern culture and to provide an alternative and ambivalent reading of the power relations implicit in work exploring identities by art and design students. Specifically I look at the position of gay and lesbian students and teachers, and ask whether their sexuality can figure within the injunction 'explore your identity'. Given the heteronormative culture of schooling, I end by recommending that individuals should be wary of outing themselves in the name of self-expression but that art teachers could use strategies of distancing to engage students with issues of sexuality and join with others to counter homophobia by queering the curriculum.
\end{abstract}

\section{Introduction}

Art and design teachers in secondary schools are increasingly concerned to understand how their subject can contribute to the emerging consensus over inclusive education. UNESCO define this approach as one that 'looks into how to transform education systems in order to respond to the diversity of learners. It aims to enable both teachers and learners to feel comfortable with diversity and to see it as a challenge and enrichment in the learning environment, rather than a problem.'(1) Increasingly it is being argued that sexuality should appear alongside those categories of difference such as class, disability, ethnicity, gender, that have proved prejudicial to equality of opportunity for young learners.(2) It was in relation to these concerns that I wrote a paper (published in this journal, 2005) examining the way a fifteen-year-old student explored her emerging lesbian identity through the opportunity provided by the GCSE 'expressive module'.(3) My argument critiqued those prevailing understandings of the expressive that revolve around the notion of an indivisible self whose essence unfolds through a process of self-revelation. In contradistinction I was at pains to stress the coded and communicative function of expressive acts so as to highlight their social, interactive and interpretative uses. However, some things were left unsaid and I want to look again at the implications of what may be construed as the valorisation of a confessional culture. Specifically I wish to unravel the contradictory practices in secondary art and design where the concept of identity is explored in 
conjunction with the 'self' a dual presentation that is, in most instances, heavily selfcensored, especially in relation to non-heteronormative, queer sexualities. If the injunction, 'explore your identity' is so quickly and easily invoked in art and design, what does identity mean in this context?

Identities: essence or construction

For many people an identity is a precious thing. As a term within traditional western philosophy it has come to signal the very essence of a person or a group of people, a name that sums up a way of being in the world. The outward emanations of this essence therefore function to inform others about what and who a person is, it denotes both their status in society and their individuality, what is sometimes referred to as a selfhood. This identity, a co-product of classical citizenry, theological notions of the soul and bourgeois notions of autonomy and self-actualisation, coalesces and solidifies into the figure of the unique and self-affirming individual, a concept that even today, in a mature capitalist, liberal democracy, seems to many entirely 'natural' and positive. And yet this affirmation is often achieved at the expense of others so that the key to this identity can be found in the binary opposition, 'sameness and difference', in human terms the exclusionary 'us and them'. As Jeffrey Weeks asserts, identities 'are personally knitted together into narratives which give coherence to individual lives, support and promote social agency, and express certain values, values which we share with those with whom we identify, and which differentiate us from countless others with whom we do not, often cannot, identify'.(4) With this in mind, any consideration of identities outside a cohesive, social structure (for example, across national and cultural boundaries or between social and political communities) conjures a symbolic space of difference where the substance, the truth of a person resides. For many people this truth is inviolable, sacrosanct; to question its authenticity is to deny the owner their historical inheritance and subjectivity. It is no wonder then that this space is frequently a site where the most extreme forms of power are consolidated and resisted. As such, identities are often carefully nurtured and reproduced, treasured and reinforced; they come to signal a sense of self-determination. However, there are many historical instances where identities have not been self-generated but designated by others (a process that Louis Althusser calls 'interpellation'(5) and sometimes, as Michel Foucault argues, pathologised.(6) In such instances these identities have been received as one part of the apparatus of oppression and are inevitably contested, fought over, lost, won.

In British schools, the notion of identity tends to be raised in relation to humanist principles of self-affirmation and multicultural celebration. Art and design it is thought provides a useful vehicle for such exploration because, in relation to multiculturalism it can provide kaleidoscopic and often ahistorical exemplars of confirmatory difference and in relation to self-affirmation it provides a history in which the western artist has come to epitomise the ideal of fulfilled selfhood. This is not surprising given that the humanist notion of an essential-self revealed through a series of expressive actions is central to the way the artist has come to be understood and cherished in western modernism.(7) Within the tradition of expressivism the artist is supposed not only to represent aspects of her or his cultural identity (Hegel's 'volksgeist') but to deposit traces of self, a concretisation of their subjectivity. This sense that the self can be communicated through metaphoric equivalence rather than coded representation suggests that the self is something like an embodied possession, something integral and fixed despite the fact that it can be described and identified, paraded or denied. Yet, although these outward signs are trappings that can be taken away, the essence, it is affirmed, the inner core, must always remain the same. During 
the first half of the twentieth century, when expressivism was at its most belligerent in the visual arts, these understandings of the self were being profoundly critiqued within structuralist theory where the self, or a person's subjectivity, was theorised not as a fixed entity but as a determined position within a system such as the unconscious (8) or kinship (9). More recently, within poststructuralism, the idea of an essential self has been further questioned so that identity is theorised as a product of discourse (10) or as a contingent configuration fashioned and refashioned in any number of forms, for example as a set of desiring practices, a vehicle for performance or a strategic and possibly queer response to a situated and seemingly determined existence (11). What all these theories share is a sense that the self as realised through a person's identity is something constructed in relation to the affordances (the constraints and potentialities) of a given situation, a somatic and psychic process of social and cultural interaction within which the individual may or may not have agency. The resultant network of relationships is thus a contingent and changing arrangement of feelings, behaviours and signals that makes any attempt at analysis complex and problematic. Stuart Hall refers to identity as:

the meeting point, the point of suture, between, on the one hand, the discourses and practices which attempt to 'interpellate', speak to us or hail us into place as the social subjects of particular discourses, and on the other hand, the processes which produce subjectivities, which construct us as subjects which can be 'spoken'. Identities are thus points of temporary attachment to the subject positions which discursive practices construct for us (12)

Foucault supposes that an identity is the designation resulting from the social and cultural processes through which the child gradually becomes a 'subject'.(13) Likewise Hall examines the active process of identity construction, what he calls 'identification', 'a process never completed... and since as a process it operates across boundaries, it entails discursive work, the binding and marking of symbolic boundaries, the production of 'frontier effects'. It requires what is left outside, its constitutive outside, to consolidate the process.'(14) The process of 'othering' implied here is a type of negative identification, a means by which a group of people confirm who they are by asserting what they are not and often by projecting their own perceived faults onto others designated 'not us'. Othering is a particularly prevalent tool within the normalising function of schooling and it is within this process of normalisation that the seemingly benevolent othering practices of multicultural celebration and homosocial bonding can turn out to have pernicious effects. But before turning to these it is important to establish the role of art, visual culture and art education within identity construction.

Identities: visual culture and art education If one accepts the notion that an identity is something constructed rather than something with which a person is born, then identities are less like objects and more like social practices, a series of semiotic processes that have to be negotiated and made visible to function effectively. It is therefore within visual culture that their performance is particularly apparent and it is also here that their distinctiveness is most easily celebrated, especially within the context of multiculturalism. But this immediacy and difference has the potential to cause strong reactions and these are not always positive; in England and France recent prohibitions over the wearing of the hijab by Muslim school girls and the subsequent debate is evidence of this. It could therefore be claimed that visual culture, particularly the body as a site for inscription, is the vehicle through which identities are made to perform 
their most spectacular acts or, less often, moments of self-effacement or denial. Within the liberal traditions of art education and the wider context of democratic schooling in Britain any person wishing to explore the concept of identity must therefore recognize the school as a 'community of individuals', a place where difference and diversity is both an expectation and a goal. This is not to renege on the poststructuralist theories referenced above in which each person is constructed as a subject through an engagement with their material and cultural specificity. Rather, as Atkinson argues, it is 'difficult to ignore the point that some understanding of agency is required when considering action and change particularly in the field of art practice which, historically, is premised upon notions such as self-expression and individuality'.(15) In other words, despite the restrictions of a person's social conditions, within education, and specifically art and design, representational and productive resources can 'be utilised for exploring and developing... understanding of difference, co-existence and cooperation'.(16) It is here, therefore, at the very centre of the pedagogic principles for art and design, that an implicit argument for inclusion can be found: all are welcome; all must be heard. This is the rhetoric; but within and outside the classroom what happens in practice?

Identities: performance and denial in the art room

When art teachers ask Key Stage 3 students to explore their identities their initial instruction is often framed by a multicultural subtext in which students are encouraged to focus on visual signs of difference, presumably in the assumption that this 'celebratory' approach will build both self-esteem and tolerant and positive relations (17). The vehicle for this strategy is frequently self-portraiture, a genre through which students represent aspects of their appearance and in so doing supposedly reveal an understanding of both selfhood but also how s/he would wish to be seen by others. In this process students draw on the canonic exemplars of western and classical portraiture, an iconography in which symbolic attributes complement the appearance of the depicted subject. But in art and design the meaning of this iconography is often overlooked in favour of the technical and formal procedures that constitute 'style'. In order to relate their appearance to the stylistic features of canonic exemplars and to a sense of themselves as gendered and raced, social beings, students inevitably have recourse to the contemporaneous visual resources of the mass media and particularly advertising, a ubiquitous discourse through which they are constructed as desiring consumers. Students tend to assemble around or within the central figure (delineated with or without mirrors or photographic reference) those essentialist signifiers provided by the mass media and/or historical art. These processes of appropriation and accumulation invite students to redeploy what may amount to stereotypical representations of difference in the name of formal and stylistic exploration. This emphasis on formal procedures divorced from any conscious meaning making encourages students to avoid critical and investigative work so that primary markers of identity such as religion and culture, nationality and race may become conflated, as may gender role and sexual identity. At the same time any notion of sexuality as an aspect of self (that is both a person's realisation of erotic desire and their potentiality as a desiring subject) is displaced onto unconscious signifiers and often fetishised in the form of consumer products. This aspect of students' identity tends to be out-of-bounds, particularly because the period of puberty and the realisation of developing sexual desire produces a period of uncertainty in the context of British society with its strange mix of institutional prohibitions and commercial excitations. 
If the sexual practices of the young are themselves somewhat taboo, territory to be avoided as something outside the purview of formal discussion and self-representation, nonetheless, normative destinations and potentialities, those of marriage or the body beautiful (be they seductive and or athletic) can be accommodated because their normative status and ubiquity hides their sexual basis. This is not surprising given that the developmental period known as adolescence, especially in educational research, is predominantly seen as a period of transition, a dangerous in-between where the child gives way to the adult, a relocation that is delicate and possibly risky.(18) Whenever there is risk, caution and avoidance are the preferred strategies, both from teachers and students themselves. However, in GCSE art and design 'personal response', enshrined in the Assessment Objective 4, is the guiding principle (19). Often the theme which acts as the hook for this response is mediated through the work of modernist, twentieth century artists: in my experience Dali, Freud, Khalo, Klimt, O'Keefe, Picasso, are particular favourites, and it is therefore not surprising that sexuality figures in these responses albeit hidden within the formal signifiers of a specific 'style'. In this way the sexual significance of the image is partially masked, distanced from the students' desires and subjectivity, and they therefore come to learn how to represent these complex feelings, latent or realised, as mediated by the representations of others. Again, this is not surprising for in looking at the self there are real dangers, after all the majority of students following GCSE are under the age of consent; the visibility of their own sexual practices is therefore strongly self-regulated depending on context. It follows that any sexual identity falling outside heterosexual relations is difficult to accommodate within the normalising regimes of representation that the art and design curriculum endorses. Thus, despite the recent liberalisation of the law (20) homosexual identities are a case in point.

Despite students' understandable repression or disavowal of their sexuality in the formal school context they are also aware of prevailing counter-discourses that, unlike the production of the 'false' desires aimed at by advertising, aim to expose the 'realities' of contemporary living. These discourses are exemplified by two forms: one, a genre of 'fantasy' which works allegorically in relation to contemporary mores (eg. Buffy the Vampire Slayer) and two, the culture of confession that permeates 'live' TV (eg. Jerry Springer; Big Brother). It is against these popular forms that students measure and discuss their emerging sexualities, for as Louisa Allen finds students do discuss sexuality among themselves. (21) These discourses provide a parallel, more illicit model than school sex education proffering the sexual mores of a predominantly young, urban milieu. 'Live' TV in particular produces an entertainment where the 'ideal' of normative relations, the monogamous heterosexual union of reproductive marriage (still woven into advertising as well as the moral and health discourses of religion and school) is reinforced through its absence. Students, however, rarely mimic the confessional idiom of TV in adult facilitated forums, avoiding conscious representations of sexuality unless they support heteronormative values (although images of homosocial bonding may veil desires that remain unspoken). Within an inclusive programme teachers therefore have to grapple with representations in which the image is deployed to maintain stereotypical relations and thereby reveal the injustices that the images mask.(22) However, despite the move towards critical studies in recent years, as I have argued, student production often demonstrates an acritical acceptance of such stereotypical forms, an acceptance that is less likely in a discursive environment where the discourses that produce sexual identities can be interpreted and evaluated. But in many art departments a culture of working-against-theclock to meet attainment targets militates against interpretative practices and thereby 
ensures that one of the strengths of art education, the process of self-exploration within a social, interactive space, is overlooked.

The difficulty also lies with the way art and design as a school subject has accrued to itself an identity based solely on making, a making often predicated on clear outcomes replicated through exemplification and prototypes. Later in a student's school career it is difficult to break the cycle of dependency that this process encourages. But, both in general and specifically in relation to the focus of this paper, this orthodoxy could be challenged by engaging students in discussion and investigative practices: in this instance with the process of identity formation and the way people (not the students themselves) represent identity through visual signs. Such signs can refer to a whole range of biological, social and cultural categories, some seemingly self-evident, some problematic, indeed, such categories can accumulate in relation to any one person depending upon who is doing the naming and when and in what context it is taking place. Consider, for example, identities based on age, class, disability, ethnicity, gender, nationality, politics, religion, sexual orientation. None of these is absolutely fixed in a temporal sense and within any one person there may be contradictions and tensions, as Hall argues '...identities are never unified and, in late modern times, increasingly fragmented and fractured; never singular but multiply constructed across different, often intersecting and antagonistic, discourses, practices and positions.'(23) When understood in this way the term identity is somehow more permeable, more possible, more movable than is suggested by the idea of the immutable self. But this disjunction is rarely questioned in secondary art and design, if it were, identity would be explored not as an essence or a social/cultural designation but as a resource affording the 'owner' the opportunity to identify with, or to adopt and perform identities when and where they think fit. But the processes implied here: those of adoption, appropriation, multiplication, seem to defy the idea of fittingness, or indeed fitness; their artificiality offends the theocratic and liberal humanist ideals respectively of the soul and the true self. Because of this enduring legacy and despite the call for self-affirmation, examination or unfolding, in schools some identities seem not to fit, well not comfortably in any case.

Gay and lesbian identities in school

Within the heteronormative culture of British schools heterosexuality and its supposed reproductive function is the unspoken norm. As a norm, the given against which all other sexualities are compared and thus designated perverse, it needs no name, a muteness that affords its adherents the right to primary identities that are not sexual (although of course they may be gendered and may well fall within an oppressed group). Once assigned to a student or a teacher, any sexual orientation other than heterosexuality is somehow imagined at the very core of that person. Although this sexuality defines both a mode of desiring and a practice, the heternormative world assumes that a non-heterosexual sexuality must define a person's very subjectivity, must overwhelm and subsume all other characteristics. In other words a gay or lesbian student before being a young man or woman, a Christian or a Jew, is quintessentially queer. But, as Elizabeth Grosz points out:

In the case of homosexuals, I believe it is less a matter of who they are than what they $d o$ that is considered offensive... It is this split between what one is and what one does that produces the very possibility of a notion like 'the closet', a notion which hinges on a separation between private and public and which refuses integration. Moreover, it also accounts for the very possibility of coming out - after all, a quite ridiculous concept in most other forms of oppression. This is what 
enables homosexuals to 'pass' as straight with an ease that is extraordinarily rare for other oppressed groups. Homophobia is an oppression based on the activities of members of a group, and not on any definitive group attributes. (24)

If this is so, it is not surprising that those students whose developing sexual orientation falls outside the norm will tend to avoid a queer label when invited to represent their identity in art and design. They are unlikely, for example, to deploy symbols of same-sex couples and alternative family structures, whereas students who feel comfortable with a 'straight' label can deploy the sexual symbols of marriage and fertility with impunity. Within the heteronormative culture of the art room, despite its rhetoric of self-expression, to parade a queer identity would seem courageous, some might say foolhardy. Just so in the wider community of the school where gay, lesbian, bisexual and transgender (GLBT) students and staff are subject to harassment, including taunts, ridicule, censor even physical assault, a risk to normative values. In a different more inclusive regime, and under the benevolence of a concerned adult, GLBT students may also be seen as risky, not as a risk to others but at risk from others, another possible school-refuser or suicide (for statistics see Nick Stanley in this volume). Given this scenario evasion or denial would seem a more comfortable strategy for students and teachers, a ritualistic performance of heteronormativity leaving the onlooker none-the-wiser. And yet, within the framework of 'freedom' foregrounded in the National Curriculum (25) this masquerade could be perceived as an unhealthy game to play. To know and yet to deny an identity that others consider both essential and peculiar, unwitting yet wilful, is somehow not to play the game, especially within a confessional culture where accountability is a prime virtue. Why should this be so?

Foucault and the confessional discourses of sexuality In part 1, 'The Will to Knowledge' Michel Foucault locates the production of modern discourses on sexuality in the Christian pastoral, that is the confessional mode introduced by the Catholic Church during the seventeenth-century. Despite new discretions and expurgations, the priest's duty was to unveil not just the sexual acts of the penitent but also their desires, and in this way there was a proliferation of discourses on sex. Everything was to be recorded in the form of speech, which, transformed through this process into knowledge, became subject to 'effects of mastery and detachment'.(26) The confessional therefore provided all subjects with an internalised apparatus with which to survey and regulate their desires. 'Saying it all' was to take on different forms as Europe developed towards secularised, bourgeois governance. In the eighteenth-century for example, rationalists found ways to accommodate sex within the emerging and consolidating discourses of Enlightenment: 'Sex was not something one simply judged; it was a thing one administered. It was in the nature of a public potential; it called for management procedures; it had to be taken charge of by analytical discourses'.(27) In other words sex, from childhood to old age, was now objectified and policed not just for the salvation of the soul but for the public good, it was as much an economic and political imperative as it was a moral one. It was therefore necessary to establish and perform sufficiently serious public and pedagogic discourses to reflect the significance of sex and to ensure codified apparatus, medical and juridical, for its efficient regulation. In bourgeois morality those sexualities that did not conform to the procreative practices of heterosexual marriage, 'to the strict economy of reproduction', were often denied or marginalised, hidden within spaces where 'illegitimate' or 'perverse' voices could be heard and studied scientifically (psychiatry) or used for profit (prostitution, pornography). However, as with the pastoral, the very apparatus deployed to police transgression simultaneously named and codified it, 
constructing illegitimate identities, a discourse of illicit pleasures and a culture of 'sexual heterogeneities'.

The visual arts were one site where these codifications took place, where the diversity of human sexuality was recorded and named, from illustrations in the early nineteenth century of the polymorphously perverse fantasies of de Sade to the photographic record of hysterics at the St Saltpêtrière clinic. Within the European academies, the patriarchal bastions of national and bourgeois morality, the study of the female nude gradually supplanted the male to become the form that signalled the highest, purest most disinterested practice, a usurpation in which any sexual significance was disavowed (28) (a practice that is still common to this day in sixth form life classes). This status was immediately questioned by artists from both within and outside the academy's walls as they conjured the nude as the femme fatale of biblical and classical history or situated her in the sexualised milieu of the demi-monde, the harem and the brothel, depictions not of modesty or propriety but of excess, concupiscence and degeneration.(29) Towards the end of the nineteenth century the supposed destruction wrought by such women on the morals and health of the youth of the day was joined by the predatory menace of the newly named 'homosexual', who, unlike his vigorous brother, was epicene, wan and pleasure obsessed; the trial of Oscar Wilde in 1895 brought this characterisation fully into public consciousness. It should be remembered that before the 1880s it was not the person, e.g. a homosexual, whose sexual identity was illegal it was the doing of so-called bestial or depraved acts and these could be practised (physiology allowing) by any person. Only with the coming of sexology, as Foucault reveals, were these acts deemed inherent to a particular person, the invert, the pederast and so on. In response to the various public panics of the fin-de-siècle the regimes of physical exercise already instigated in schools mid-century to counter the unhealthy energies of pubescent desire were intensified for boys and the image of the athlete joined with that of the gentleman as the role model to which to aspire. For girls a different regime was in place where they were 'largely educated at home for a role in preparation for private and domestic life.' (30)

In the twentieth-century it could be said that psychoanalysis merely intensified this process of speaking and making visible, thus valorising the power/knowledge relations that both proscribe and produce pleasure:

The pleasure that comes of exercising a power that questions, monitors, watches, spies, searches out, palpates, brings to light; and on the other hand, the pleasure that kindles at having to evade this power, flee from it, fool it, or travesty it. The power that lets itself be invaded by the pleasure it is pursuing; and opposite it, power asserting itself in the pleasure of showing off, scandalizing, or resisting. (31)

Here then is the game: the to-ing and fro-ing between secrecy and revelation, fear and trust, ridicule and reciprocity. It should be remembered that in Freudian terms perversion constitutes the norm, the base-line of the pleasure-seeking individual who only gradually (through a process of psychic maturation) fixes the object of desire in relation to social and cultural conventions. Perversion is, in a sense, the most 'normal' or healthy of the three fundamental psychoanalytical categories, the other two being neurosis and psychosis.(32) Here was a confessional route devoid of sin. If in the nineteenth century the artist had tended to project their desire onto the sexual activities of others, increasingly in the twentieth century they turned their attention towards their own. This process of public self- 
reflection further undermined a bourgeois economy of desire and in the explorations of the Surrealists in particular an aesthetics of perversion and fetishisation stood counter to the disavowals of the academy and the developing stereotype of the nuclear family within popular culture. After WWII, and the exponential rise of the mass media, the tenuous link between bourgeois morality and capitalist market forces eventually collapsed and with the age of advertising, video, camcorder and the internet, images of sex have saturated the visual field and command a major percentage of viewers' attention.

Schools

The massive presence of a sexualised visual culture is also denied throughout much of schooling, a space where young people are supposedly protected from the perverse attention of adults and from engaging publicly with the experience of their own developing sexualities. Suddenly, at the age of sixteen, they reach legal maturity, a time when they are given licence to explore their desires through consensual sexual practice but at a time when their understanding of sexual diversity has been largely informed by the stereotypes dominating the media and the moral regimes of home, religion, school and social services. Within the latter they are likely to have been inculcated into narratives of reproduction, prohibition and risk. These normalising discourses are the antithesis of the utopia of pleasure and the dystopia of psychotic perversion that form the two sides of the same discursive formation dominating the mass media. It may be that in art and design students have made reference to the work of artists who have explored the complexities of human sexuality, but artists are not always immune from complicity in the formation and reproduction of stereotypes. Because students are rarely empowered to investigate these works as representations, as has already been suggested they may well assimilate and perpetuate such models as givens. Within contemporary practices the place of desire, its exploration, abuse and fulfilment, does gain the serious attention of artists (not, I should add, without humour) and I have suggested elsewhere ways in which art teachers and others might engage with such work within the curriculum as a vehicle for including the erotic, that is the subjective experience of desiring.(33) But I have argued strongly for the distancing strategies of historical investigation and contemporary criticism, not confessional routes. This involves a demythologisation of the idea that art has a uniquely expressive function whereby its communicative, critical and investigative roles are overlooked. This cannot happen without the space to reflect critically on practice, not in relation to attainment targets but in relation to principles and purposes; is art and design reproductive of normative relations or can it work as a site of freedom as the rhetoric would suggest?

For most people, any process of reflection is a difficult one, particularly when cherished beliefs are challenged and threatened. There is however a danger hidden within the process of demythologisation. The critical means through which teachers might engage students in coming to know themselves as subjects constructed in, and by, history are products of Enlightenment rationality and are therefore suspect in terms of the anti-epistomological theories of some poststructuralists. But, as Terry Eagleton (a)muses, theorists such as Foucault wish to have their cake and eat it, Foucault espousing both an opposition to oppression and a paean to the pleasures of power.(34) No doubt a diagram could demonstrate the paradoxes presented by poststructuralist perspectives in the field of education; such a diagram could represent both a utopian and dystopian perspective on some of the sacred processes/artefacts of art education at secondary level so that, depending on your hermeneutic position, the very same phenomenon could be viewed as positive, 
negative or ambivalent. For example, the 'sketchbook' (officially a repository for observations, investigations and the generation of ideas) or the critical studies diary (35) could be recognised as ideal instruments for surveillance, latter day Catholic pastorals and sacraments of penance (36) apparatus through which the teacher demands confession and is thus in a position to admonish, chastise and regulate behaviours. Alternatively, the sketchbook/diary could be argued as a site for self-reflexivity, an opportunity for an aesthetic working on the self that enables the student to achieve 'the perfect supremacy of oneself over oneself' (37), a process in which the critical and productive are blissfully indivisible. But neither the conspiracy nor the epiphany rings true. Where do we go from here?

\section{Conclusion}

Identities, I have been arguing, are a fluid arrangement of contingent identifications through which a person, or a group of people, negotiate (or have imposed for them) a place within specific social situations. To put it another way, an identity is something constructed within the affordances of a given culture and in dialogue with the biological as well as social potential of each individual. These identities fluctuate in relation to space, from the familial through the local to the global, and in relation to time, from infancy to death, producing a complex network of symbolic relations. Fixing such identities tends to serve the function of reproducing exisiting power relations so that people both know and often accept their place in a given situation. But by accepting that an identity is something constructed it becomes open to change. What may have been being preserved as an absolute (for example, the natural status of heterosexual relations) becomes permeable and thus the notion of difference, diversity and multiplicity potentially less threatening (although this erosion is seen as a mighty danger for those in positions of power because it could so easily upset the status quo).

Art and design teachers could possibly create a sanctuary in which difference can be voiced, questioned or celebrated but it would be dangerous to do this in isolation. Providing a locus for confession within the context of a wider oppressive culture might lead students to be needlessly exposed to aggression. This signals the need for art and design teachers to develop an inclusive curriculum through collective action, for example by engaging with whole school forums, joining equal opportunities committees and by providing resources for generic educational provision such as PSHE, Citizenship and Sex and Relationship Education in which the desiring individual can be located within the dominant conventions and customs of their specific history and culture. This points to the need for some guiding texts and resources. I feel an action research project coming on; anyone join me?

\section{References}

1. UNESCO (2003) 'Overcoming Exclusion through Inclusive Approaches in Education: A Challenge and a Vision’ (conceptual paper) http://www.unesco.org/education/inclusive accessed 10.4.06

2. Loutzenheiser, L. W. and MacIntosh, L. B. (2004) 'Citizenship, Sexualities and Education', Theory into Practice Volume 43, Number 2, Spring

3. Addison, N. (2005) 'Expressing the not-said: Art and design and the formation of sexual identities' international Journal of Art and Design Education, Volume 24, 1. pp. 20-30. 
4. Weeks, J. (2003) 'Necessary Fictions: Sexual identities and the Politics of Diversity' In J. Weeks; J. Hollands and M. Waites (eds) Sexualities and Society: A Reader. Cambridge: Polity Press. p.123

5. Althusser, L. [1971] (edition 2001) Lenin and Philosophy, and other essays. Trans. B. Brewster New York: Monthly Review Press.

6. Foucault, M. [1973] (edition 2003) The Birth of the Clinic: an archaeology of medical perception, Trans. A. M. Sheridan London: Routledge

7. Preziosi, D. (1989) Rethinking Art History. New Haven and London: Yale University Press. p. 33

8. Freud, S. [1940] (edition 2003) An Outline of Psychoanalysis. Trans. H. Ragg-Kirkby, introduction M. Bowie, London: Penguin.

9. Levi-Srauss, C. [1955] (edition 1992) Triste Tropiques Trans. J.Weightman and D. Weightman London: Cape Harmondsworth: Penguin.

10. Foucault, M. [1976] (edition 1998) The Will to Knowledge, The History of Sexuality: 1. Trans. R. Hurley London: Penguin.

11. Butler, J. (1999) Gender Trouble: Feminism and the Subversion of Identity. New York and London: Routledge.

12. Hall, S. (2000) Who needs 'identity'? In Du Gay, P.; Evans, J. and Redman, P. (eds) Identity: a reader. London: Sage. p. 19

13. Foucault, M. (1972) The Archaeology of Knowledge Trans. A.M. Sheridan London: Tavistock Publications.

14. Hall, S. (2000) op. cit. pp. 16-17

15. Atkinson, D. (2002) Art in Education: Identity and Practice. Dordrecht, Boston, London: Kluwer Academic Publishers. p. ?

\section{Ibid. p. ?}

17. Coppock, L. (2005) Art of Different Cultures: Imaginative arts and craft from around the world, London: Belair.

18. Talburt, S. (2004) 'Constructions of LGBT Youth: Opening Up Subject Positions' Theory into Practice 432

19. Edexcel (2000) Specification: Edexcel GCSE in Art \& Design. London: Edexcel. p.28

20. Civil Partnership Act $18^{\text {th }}$ November 2004 
21. Allen, L. (2001) 'Closing Sex Education's Knowledge/Practice Gap: the reconceptualisation of young people's sexual knowledge,' Sex Education 1, 2. pp. 109-122.

22. Hall, S. (1997) Representation. London: Sage in association with the Open University.

23. Hall, S. (2000) Who needs 'identity'? In Du Gay, P.; Evans, J. and Redman, P. (eds) Identity: a reader. London: Sage. p. 17

24. Grosz, E. (1994) 'Experimental Desire: Rethinking Queer Subjectivity’. In. Copjec, J. (ed) Supposing the Subject. London: Verso. pp. 150-15

25. DfEE (1999) The National Curriculum for Art and design. London: HMSO.

26. Foucault, M. (1998) [1976] op. cit. The Will to Knowledge, The History of Sexuality: 1. Trans. R. Hurley London: Penguin. p. 23

27. Ibid. p. 24

28. Solomon-Godeau, A. (19) Male Trouble: A Crisis in Representation, London: Thames and Hudson.

29. Addison, N. (2003) 'What are Little Boys Made Of, Made Of? Victorian Art and the Formation of Gender', Sex Education Vol 2, 2 pp. 171-182.

30. Dalton, P. (2001) The Gendering of Art Education. Buckingham: Open University Press. p. 35.

31. Foucault, M. (1998) [1976] op. cit. p. 45

32. Fink, B. (2003) 'Perversion' in K. A. Rothenberg, D. A. Foster and S. Zizek (eds.) Perversion and the Social Relation, Durham and London: Duke University Press.

33. Addison, N. (2006) 'Acknowledging the gap between sex education and the lived experiences of young people: a discussion of Paula Rego's 'Pillowman' (2004) and other cautionary tales' Sex Education: special edition.

34. Eagleton, T. (1990) The Ideology of the Aesthetic. Oxford: Blackwell

35. Addison, N. (2003) 'Productive tensions: Residencies in Research' In N. Addison and L. Burgess (eds) Issues in Art and Design Teaching, London: Routledge/Falmer.

36. Foucault, M. (1998) [1976] op. cit. pp. 18-35

37. Foucault, M. (1992) The Use of Pleasure. The History of Sexuality: 2. Trans. R. Hurley (1985) London: Penguin. p. 31. 